\title{
The Thin Line between Munchausen Syndrome and Munchausen Syndrome by Proxy
}

Ferrara $\mathbf{P}^{1 *}$, Vitelli $\mathrm{O}^{2}$, Romani $\mathrm{L}^{1}$, Bottaro $\mathbf{G}^{2}$, lanniello $\mathrm{F}^{1}$, Fabrizio $\mathbf{G C}^{1}$, Vena $\mathrm{F}^{2}$, Del Volgo $\mathrm{V}^{2}$, Caporale $\mathrm{O}^{2}$, Pecoraro $\mathbf{R}^{2}$, Miconi $\mathrm{F}^{2}$, Masci $\mathbf{M}^{2}$, Leone $\mathrm{A}^{2}$, Guadagno $\mathrm{C}^{2}$, Amato $\mathbf{M}^{2}$, Sbordone $\mathbf{A}^{2}$, Cutrona $\mathbf{C}^{2}$, Spina $\mathbf{G}^{2}$, Perrone $\mathbf{G}^{2}$, Basile $\mathbf{M}^{2}$ and $\mathbf{G a t t o}^{\mathbf{A}^{1}}$

1 Institute of Pediatrics, Catholic University of Sacred Heart, Rome, Italy

2Service of Pediatrics, Campus Bio-Medico University, Rome, Italy

\section{Abstract}

Factitious disorders are the intentional production of feigning symptoms or disabilities; either physical or psychological. We report the case of a young girl, victim of Münchausen by proxy who became a Münchausen patient.

Keywords: Factitious disorders; Münchausen syndrome; Münchausen syndrome by proxy

\section{Introduction}

Factitious disorders (FD) are the intentional production of feigning symptoms or disabilities; physical or psychological, aroused in a person who aims to assume the patient role [1].

Münchausen syndrome (MS) and other FD differ from somatoform disorders (such as conversion disorder, somatization disorder and somatoform disorder undifferentiated) because in somatoform disorders there is no evidence of deceiving clinicians [2].

For the same reason FD differ from Somatic Symptom Disorder that's a reconceptualization of somatoform disorders in DSM5 [3].

The most extreme and serious form of FD, referred to as the MS, is characterized by a history of various outpatient visits and hospitalizations whose symptoms aggravated or changed following negative test results, or once the treatment had begun, patients would be overwhelmed by eager to get medical tests, operations, and other procedures [4,5]. Münchausen syndrome by proxy (MBP) is a complex and potentially fatal form of child abuse in which a parent or guardian - usually the mother - repeatedly induces physical or psychological symptoms in a child in order to simulate an illness in the latter [6]. The next paragraph presents the case of a young girl, victim of MBP who became a Münchausen patient.

\section{Case Report}

An 8-year-old female was admitted to A. Gemelli University Hospital of Rome, because of progressive symmetrical weakness, numbness, tingling sensations in the legs and walking impairment, severe enough that she was not be able to stand independently. After the girl was admitted to our Pediatric Department, a careful history was collected. The birth history was unremarkable: she was born at 40 weeks without complications; she had a normal early growth and development, good relationship with her peers, good academic results with few absences. She occasionally took medications for cough and rhinitis. The patient had no siblings. Her mother, a 38 year-old housewife, underwent postnatal repair of myelomeningocele (MMC). Her father, a 39 year-old employee, was in good health. The child had lived with her mother since the parents divorced 3 years before. She saw her father once a week and had a good relation with him. No other antecedent illness or trauma was reported within the family.

The medical history of the child revealed no bowel alterations and normal urinary output. On physical examination, the tone and the mass of the lower limbs was normal. The child was able to move her legs against gravity and against resistance. Deep tendon reflexes were readily elicited with a normal bilaterally response. Babinski signs were absent, the sensory and cerebellar system was normal. Laboratory work-up revealed no alterations: a complete blood count, tests for renal and hepatic function, creatine kinase, vitamin B12, rheumatic screening and antibodies toward acetylcholine receptor and neuromuscular junction of skeletal muscles were all found normal. Infectious diseases screening (hepatitis, toxoplasmosis, Cytomegalovirus, Epstein-Barr virus and Campylobacter jejuni), were negative. Magnetic resonance imaging of brain and spine was normal. Nerve conduction study and electromyography showed no evident nerve or muscle disorders. However, when the girl was asked to walk, she could not stand If not with assistance. The mother was introduced to the diagnostic test results. It was explained to her that they did not match the clinical picture, but the woman appeared very disappointed by negative results of laboratory tests and physical examination, insisting that her daughter had to be sick and that other evaluations were necessary.

The mother was worried that her daughter could have developed a MMC or some neurological impairment since herself had undergone post-natal repair of MMC with no consequent neurological disabilities.

We decided to show all medical records to a child neuropsychiatrist, who decided to interview the mother and her daughter.

During the interview the mother said those three years before, she had begun to show her daughter her scar, and that she had started to tell child about the possible neurological damage resulting from the procedure she had undergone. Her daughter started to act as if she had some developmental problems, increasingly limping day by day.

In order to reduce any traumatic effects on the girl and to promote a positive parent-child attachment, a familiar narrative psychotherapy was settled for them while the daughter was still in hospital: the immediate improvement of the girl, who could now walk almost normally only after the first meetings, was impressive.

A diagnosis of FD was proposed. When confronted with the diagnosis, the mother refused the possibility that the girl could pretend illness to that point and she decided to sign out against medical advice.

*Corresponding author: Prof. Pietro Ferrara, MD, Institute of Pediatrics, Catholic University, L.go F. Vito, 1, 00168, Rome, Italy, Tel: 39.06.30154348; Fax +39.06.3383211; E-mail: pferrara@rm.unicatt.it

Received January 25, 2014; Accepted March 29, 2014; Published March 31 2014

Citation: Ferrara P, Vitelli O, Romani L, Bottaro G, lanniello F, et al. (2014) The Thin Line between Munchausen Syndrome and Munchausen Syndrome by Proxy. J Psychol Abnorm Child 3: 115. doi:10.4172/2329-9525.1000115

Copyright: @ 2014 Ferrara $\mathrm{P}$, et a. This is an open-access article distributed under the terms of the Creative Commons Attribution License, which permits unrestricted use, distribution, and reproduction in any medium, provided the original author and source are credited. 
Thanks to the story of the girl's father, we subsequently gained knowledge that the girl was admitted in another hospital where the diagnosis of Guillain-Barré syndrome was evaluated. A lumbar puncture was performed and cerebrospinal fluid resulted normal. Therefore, suspecting a seronegative myasthenia gravis, she was treated with corticosteroids.

During a follow up of two years all laboratory tests remained negative and the girl started to walk better till she was admitted to a pediatric Emergency Department (ED) confined to a wheelchair pretending to be blind. Moreover during these two years she was repeatedly admitted to EDs reporting recurrent abdominal and thoracic pain and cephalalgia.

\section{Discussion}

Precise prevalence data of MS and MBP are not available in pediatric literature.

The average age of children victim of MBP is usually 48.6 months, even though there are records of cases of victims of age of 6 years [7].

Early detection is crucial because if the deception is not uncovered and the patient's faking continues, as children grow older, they will have a tendency to falsely perceive themselves as ill or defective. MS is a mental disorder that is characterized by the causing or pretending to have physical or psychological symptoms in oneself.

Adults aged 20-40 years are the most likely groups to develop MS. Women employed in medical fields, such as nursing or medical technology and men middle aged with little familial attachment, unmarried are particularly vulnerable to this disorder [8]. Munchausen syndrome is often either preceded by or coexists with Munchausen syndrome by proxy.

If our surmise is correct the mother did not primarily intend to harm her daughter showing her the scar and probably she really believed that her daughter was ill, she only wanted to draw recognition and needed attention to herself after the divorce, but with her behavior, she induced the medical provider to order numerous painful investigations and potentially toxic treatments. Moreover our patient has been brought up in the belief that she was unable to walk even if all medical examinations showed her back and legs to be normal. The mother seemed to show an affectionless control parenting style, which could stimulate the development in her daughter of improper knowledge about herself and the world. Unfortunately the mother decided to sign out, against medical advice, before we had the chance to perform a more careful psychological evaluation, that would have allowed us also to make a more accurate differential diagnosis between MS and conversion disorders, assessing if the symptoms were intentionally feigned by the patient or not.

Psychiatric evaluation would be important also because to not find a medical explanation for child's disease doesn't mean, automatically, that it is a psychiatric disorder. In fact many functional syndromes seem to be due to endocrine or neurological dysfunctions [9].

With this paper we aim to alert pediatricians to include MBP on the differential diagnosis as soon as possible, not only because during the process of medical investigations morbidity and sometimes mortality may be high, but also because victims may become themselves MS patients growing-up [10-12]. Better understanding and identification may be difficult for physicians in suspecting deception by children, primarily when a parental coaching or collaboration is suspected. Further study may help to provide more effective interventions [13]. Furthermore, by reporting this case, we hope to have underlined the importance of communication especially the sharing of information among different hospitals since the child, first victim of MBP and then suffering from MS, received steroid for suspected myasthenia gravis, a very risky treatment.

\section{References}

1. Feldman MD, Hamilton JC, Deemer H (2001) Factitious disorder; in somatoform and factitious disorders. Philipps KA (edn) Review of Psychiatry American Psychiatric Press, Washington, DC, 20: 129-159.

2. Lipsitt DR (2007) Factitious disorder and Münchausen syndrome.

3. Dimsdale JE, Creed F, Escobar J, Sharpe M, Wulsin L, et al. (2013) Somatic symptom disorder: an important change in DSM. J Psychosom Res 75: 223228.

4. Asher R (1951) Munchausen's syndrome. Lancet 1: 339-341.

5. Turner J, Reid S (2002) Munchausen's syndrome. Lancet 359: 346-349.

6. Meadow R (1977) Munchausen syndrome by proxy. The hinterland of child abuse. Lancet 2: 343-345.

7. Sheridan MS (2003) The deceit continues: an updated literature review of Munchausen Syndrome by Proxy. Child Abuse Negl 27: 431-451.

8. Jaghab K, Skodnek KB, Padder TA (2006) Munchausen's Syndrome and Other Factitious Disorders in Children: Case Series and Literature Review. Psychiatry (Edgmont) 3: 46-55.

9. Sharpe M, Carson A (2001) "Unexplained" somatic symptoms, functiona syndromes, and somatization: do we need a paradigm shift? Ann Intern Med 134: $926-930$

10. Rosenberg DA (1987) Web of deceit: a literature review of Munchausen syndrome by proxy. Child Abuse Negl 11: 547-563.

11. Bursch B, Schreier HA, Ayoub CC, Libow JA, Sanders MJ, et al. (2008) Further thoughts on "Beyond Munchausen by proxy: identification and treatment of child abuse in a medical setting". Pediatrics 121: 444-445.

12. Ferrara P, Vitelli O, Bottaro G, Gatto A, Liberatore P, et al. (2013) Factitious disorders and Munchausen syndrome: the tip of the iceberg. J Child Health Care 17: 366-374.

13. Libow JA (2000) Child and adolescent illness falsification. Pediatrics 105: 336342 . 